\title{
BUSINESS PLATFORMS FOR AUTONOMOUS VEHICLES WITHIN URBAN MOBILITY
}

\author{
FABIO ANTONIALLI ${ }^{1,2,3}$, RODRIGO MARÇAL GANDIA ${ }^{1,2,3}$, JOEL YUTAKA SUGANO $^{2,3}$, \\ ISABELLE NICOLAÏ ${ }^{1} \&$ ARTHUR DE MIRANDA NETO ${ }^{3}$ \\ ${ }^{1}$ Laboratorie Génie Industriel (LGI), CentraleSupélec, France \\ ${ }^{2}$ Post-Graduate Program in Administration (PPGA), Universidade Federal de Lavras, Brazil \\ ${ }^{3}$ Terrestrial Mobility Laboratory (LMT), Universidade Federal de Lavras, Brazil
}

\begin{abstract}
With mobility becoming a key factor affecting citizens' well-being and quality of life, innovative schemes such as peer-to-peer (P2P) ride-hailing and Mobility-as-a-Service (MaaS) could have significant impacts on the urban commute. Furthermore, the insertion of autonomous vehicles (AVs) promises a positive impact on cities' transit worldwide. Ergo, companies are now combining bundles of products and services emphasizing their "sales of use" rather than of products: such integration may be realized by having multi-sided business platforms. The purpose of this study is to create future scenarios for $\mathrm{AV}$ business platforms within urban mobility contexts. Based on an exploratory descriptive qualitative research design, we collected data on academic and grey literature. Four scenarios were plotted with real-world examples currently present in urban mobility cases, extrapolated to a future reality where AVs are considered a transport mode: (A) business-to-consumer (B2C) autonomous ridesharing; (B) P2P autonomous ridesharing; (C) B2C multimodal mobility; (D) B2C + P2P multimodal mobility. Scenarios A and B entail unimodal mobility via autonomous ridesharing, whereupon in the former, a single firm owns a fleet and subsidizes the consumer segment, while in the latter, ordinary peers own the AVs, which are offered to other peers via Uber-like applications. Scenarios $\mathrm{C}$ and $\mathrm{D}$ entail multimodal mobility from point $\mathrm{X}$ to $\mathrm{Y}$, where in the former, a single firm owns the multimodal fleet and subsidizes the consumer segment, while Scenario D offers a bundle of $\mathrm{B} 2 \mathrm{C}$ and $\mathrm{P} 2 \mathrm{P}$ solutions under the MaaS paradigm. We conclude that in scenarios $\mathrm{A}$ and $\mathrm{B}$, value creation can be solely explained by business platforms theory; while in scenarios $\mathrm{C}$ and $\mathrm{D}$, business platforms theory is tied to business ecosystem theory, to explain value creation and distribution. Lastly, besides the unlikelihood of scenario C, any of the other three have the potential to become a reality when AVs become an urban transport mode.
\end{abstract}

Keywords: autonomous vehicles, business platforms, scenario planning, traffic, transportation, urban mobility, urban planning.

\section{INTRODUCTION}

Current mobility regimes based on fossil fuels and mainly individual commute are reaching their environmental, economic and social limits. For this, privately owned cars are becoming more and more challenged as a solution to mobility needs [1]. Traditional transport models could suffer an exponential decline, since we are moving away from ownership-based mobility and towards transportation systems where users want to choose their form of mobility rather than being subjected to it [2]. With that, new economic models are emerging. Companies are now combining bundled offerings of products and services in a market proposition where the emphasis is on the "sale of use" rather than the sale of products [3].

Among the various emerging alternatives, solutions such as peer-to-peer (P2P) ride-hailing (e.g. Uber, Lyft, Didi Chuxing), have rapidly emerged and gained ground as alternative modes of getting transportation, providing partial solutions to mobility issues [4]. Another interesting emerging solution is the concept of Mobility-as-a-Service (MaaS). This model delivers a flexible commute via a single interface of a service provider, by combining different transport modes that offer tailor-made mobility packages [5], [6]. 
It is expected that the car of the future will be electrified, autonomous, shared and connected. With such vehicles forecasted to become a reality in the 2030-40s [7], autonomous vehicles (AVs), are likely to positively impact on urban mobility. Therefore, the implementation of innovative mobility schemes can have a significant impact on the existing business models for public transportation, especially when it comes to integration with private transport providers [5]. Such integration may be realized by using the so-called multi-sided business platforms, which are aimed at creating value by orchestrating interactions between external producers and consumers [8]. Thus, facilitating interactions between travelers and suppliers of transport services in an improved or smarter way.

Given the aforementioned, the following question emerged: what will be the future scenarios of urban mobility with the insertion of AVs as a mode of transport? By considering as study object the business platforms for AVs in large centers where there is a need for mobility solutions, the present study aims at creating future scenarios for the business platforms of AVs in urban mobility contexts.

Besides this introduction, our paper is structured as follows: Section 2 provides a panorama on urban mobility and the challenges towards autonomous servitization, as well as that it introduces the concept of multi-sided business platforms. Section 3 presents our research methodology, pointing out the steps required to perform this study. Section 4 presents the results and discusses the analyses in two stages: a proposition of four scenarios, concerning multi-sided platforms, concepts and transport modes; and a description of each scenario with real-world examples, considering AVs as a transport mode. Finally, in Section 5 we present our concluding remarks, summarizing the main findings and highlighting the possibilities for future research.

\section{LITERATURE REVIEW}

\subsection{Urban mobility: challenges towards autonomous "servitization"}

Mobility plays a central role in ensuring prosperity and social cohesion, as well as influencing urban geography by defining where people work, live, and consequently; on how they commute [9]. Yet, by considering our highly motorized and car-dependent society, mobility is also a source of major problems in urban areas, such as: congestion, air pollution and noise; hence, contemporary transport practices are increasingly compromising the well-being of existing populations, and perhaps most importantly, the way we travel today is constraining and compromising the environment of generations to come [10].

One promising emerging solution for answering these demands is the concept of MaaS. Besides being a very recent construct [13], it presents a shift from ownership-based mobility regimes towards access-based ones [5]. With the aim of offering customized transport services to fit individual traveler's needs, MaaS delivers multimodal tailored-made mobility packages via a single interface of a service provider [11], [12].

With autonomous ride-hailing schemes likely to become a reality within the next decades [7], such vehicles are bound to ease relocation efforts on MaaS schemes, since AVs are able to rebalance themselves in a network and coordinate their actions at a system-wide level [13]. Furthermore, according to Tasha Keeney (researcher analyst on industrial innovation at ARK Invest), MaaS platforms in the context of AVs will be one of the most valuable investment opportunities in public equity markets, exceeding over 10 trillion dollars in gross revenue by the early 2030s [14]. Thus, the trend towards putting AVs on the road is rapidly gaining momentum across a broad front that encompasses original equipment manufacturers (OEMs), suppliers, mobility providers, technology companies, academic institutions, 
governments and regulatory bodies [15]. These new AV trends are concomitant with the generalization of the so-called "service economies" or "sharing economy" where owning a car will no longer be seen as a priority. Hence, vehicles will increasingly be shared and their "mobility" function is bound to become the goal in market and business analysis.

In this context, OEMs find themselves obliged to form alliances with new entrants, often far removed from their core business, such as: Google, Baidu, Uber, Lyft and Didi Chuxing, among other tech-companies [16]. Therefore, manufacturers are combining products and services [3] (a concept known as product-service systems (PSS); see: Tukker [17]) in order to provide greater value to consumers and to facilitate longer, more profitable business relationships.

Such an integration of products and services may be realized by using the business models of multi-sided platforms, such that innovations on urban mobility are not only about the integration of mobility services, but also require a complete restructuring of the supply chain for mobility service providers [5].

\subsection{Multi-sided business platforms}

Multi-sided business platforms are responsible for a revolution that is affecting many industries across the globe, they are an important business phenomenon that has existed for a long time, but over the past 7-8 years have proliferated, with the widespread use of information and communication technologies (ICTs) [8], [19]. As an example, three of the world's five largest firms as measured by market capitalization; Apple, Google and Microsoft, all run platform business models [8].

If ICTs had not come up, we would still be stuck in "pipeline business models," which until recent years had been the prevailingly dominant business model, wherein value is created in a linear fashion, with centrally employed staff and owned assets [8]. Unlike the pipeline model, multi-sided platforms create value by orchestrating interactions between external producers and consumers [8], [18]; therefore, the role of multi-sided platforms is to bring together two or more distinct, but interdependent, groups of people or entities, creating value by connecting such groups without necessarily having possession of any transacted asset [18], [19]. Thus, in simple terms, a platform is nothing more than a huge network of relationships between organizations around a core technology [23]. It is a co-evolving system composed of three main key stakeholders: the platform operator, the ecosystem of producers and the ecosystem of consumers; all connected by an interface that seamlessly links such complementors to the core [8].

With smart mobility services evolving from closed to more open structures, they are encompassing not only platform business models, but instead, an ecosystemic business approach [20]. Ergo, the business ecosystem approach covered in Moore [21] is a promising theoretical lens to assess smart urban mobility services. In the sense that modern businesses are viewed not as members of a single industry, but rather part of a business ecosystem that crosses a variety of industries that include customers, suppliers, competitors, and other stakeholders. These co-evolve their capabilities and roles, and tend to align themselves with the directions set by one or more central companies [21], [22].

\section{RESEARCH METHODOLOGY}

With the aim of creating future scenarios for AVs' business platforms within urban mobility contexts, our present research was characterized as being qualitative and of an exploratory-descriptive nature [23], [24]. The first step that was carried out, was the collection of secondary data (both on academic and grey literature), in order to subsidize 
scenario creation and discussion, and saturation criteria was seen as a stopping point [25]. Next, our data was structured and analyzed (via descriptive qualitative analysis and categorical content analysis) [26].

The following stage was dedicated to scenario creation, in which we opted to use as inspiration the pharmaceutical industry example given by Osterwalder and Pigneur [18], as well as the automotive value chain in 2025 used by Helbig et al. [27], the deployment scenarios for higher-order automated vehicles seen in Beiker [28], and the future states of mobility from Corwin et al. [29], by plotting four different scenarios on a cartesian plane, guided by two main drivers, the $x$ and $y$ axes.

Next, in order to explain and detail each scenario, four hypothetical examples were drawn based on real-world business platform initiatives that are present in urban mobility today, such as the ones exemplified by other studies [5], [6], [12]; however, extrapolated to a future reality where AVs are seen as a usual transport mode. It is worth highlighting that the present study considered for analysis SAE's levels 4 and 5 of automation. Lastly, our results were analyzed and discussed based on secondary data, in order to support the findings seen in academic and grey literature via descriptive qualitative analysis.

\section{RESULTS AND DISCUSSION}

\subsection{Scenario creation: $x$ and $y$ axes}

Consider that multi-sided business platforms create value by orchestrating interactions between external producers and consumers [19], [21]. Their success can be hindered by the so-called "chicken and egg dilemma" [8], which states that in a platform without producers that are no consumers, and vice versa [8], [18]; thereby finding a way around is crucial for any multi-sided platform's development and survival.

An escape from this dilemma is the so-called "one-way multi-sided platform" [18], where the premise is to subsidize one side of the platform (normally the customer segment). By doing so, the platform operator incurs costs to provide tools, products, services, or other benefits that will attract users (consumers) to the other side. Once there is a critical mass on one side, users will be attracted to the other, eventually leading to an inflection point (based on positive feedback loops and network effects), where "one-way platforms" become "two-way platforms", rendering mute the need for subsidies [5], [18].

With that, the $x$ axis for our scenario creation is composed on the left-hand side by "one-way multi-sided platforms" with subsidies required; and on the right-hand, by "two-way multi-sided platforms" with no subsidies required.

The $y$ axis relates to transport modes, in a sense that with new behavior patterns, uses and mobility requirements emerging, commute services might (to some extent) replace car ownership [2]. In order for these new transport solutions be achieved, policy-makers, urban and mobility planners, as well as other public and private stakeholders must undertake strong initiatives to adopt multimodal and integrated approaches [30].

The priority is to improve mobility and accessibility, while at the same time reducing the major social, environmental and economic issues caused by our prevailing mobility regimes. Therefore, it is not only necessary to improve vehicles' technology and cities' infrastructure, but also to change people's travel behaviors, with the aim of reducing dependency on private cars [12]. That being said, our $y$ axis is composed on the bottom end by a single transportation mode (i.e. going from point $\mathrm{A}$ to point $\mathrm{B}$, using only an $\mathrm{AV}$ ) and on the top end by a multimodal solution (i.e. going from A to B, using a bundle of transportation modes). Fig. 1 depicts the complete scenario array, based on two "created" drivers. 


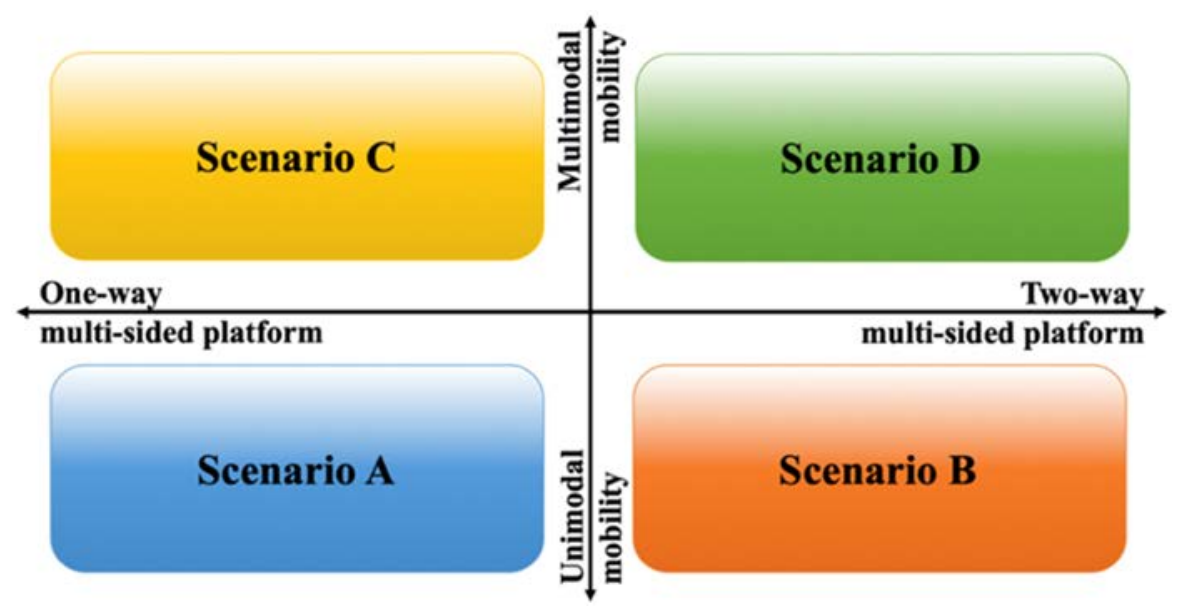

Figure 1: Autonomous vehicles: business platforms scenarios.

\subsection{Scenario A: B2C autonomous ride-hailing}

This scenario entails one-way multi-sided platforms offering a single transport mode solution. That is: one firm, by subsidizing the consumer segment, will offer complete journeys from A to B in a single transport mode. Such a scenario can be configured as a gateway for ride-hailing companies in the AVs' market. Examples here do not need to be extrapolated for a future AV reality, as the AVs are already being deployed. Companies such as Uber, Lyft and Waymo are all testing self-driving B2C ride-hailing services.

On 14 September 2016, Uber launched its first self-driving car services to selected customers in Pittsburgh [31]. Just three months later, the company began using a fleet of self-driving Volvo XC90 SUVs in its hometown of San Francisco [32], and in the year 2017, they moved the program to the city of Tempe, AZ. Nonetheless, the company announced in November 2017 that it planned to buy up to 24,000 Volvo cars that were designed to accept autonomous technology, between 2019 and 2021, in an ambitious plan that aims at moving from its current model of ride-sharing using freelance drivers, to owning a fleet of AVs [33].

In the meantime, Lyft (Uber's main competitor in the U.S.) is also in the race towards self-driving P2P services. On 4 January 4 2016, the company announced a partnership with General Motors, which has invested $\$ 500$ million as part of a $\$ 1$ billion fundraising effort to help both companies accelerate into the ride-sharing market, as well as into the AVs arena by using a self-driving fleet of Chevrolet Bolt cars [34].

Furthermore, in September 2017, Lyft announced a partnership with Ford, adding the company to its list of self-driving car partners [35]. In March 2018, they partnered with GoMentum Station (an AVs test site company) to test their self-driving technology, and later that month, they partnered with Magna (a leading auto parts supplier in North America) with the aim to co-fund, develop and manufacture AVs systems, to foster production of self-driving technology to all car manufacturers [36]. Lastly, it is worth highlighting the giant efforts of Google's sister company Waymo, a leader in self-driving R\&D with over 4 million miles driven. In 2018, Waymo placed orders for up to 62,000 hybrid-drive Pacifica minivans and 20,000 Jaguar I-Pace electric sedans, with the aim of launching B2C ride-hailing services in various U.S. cities [31]. 


\subsection{Scenario B: P2P autonomous ride-hailing}

As in scenario A, the premise here is to offer full rides from point A to B in a single transport mode. The main difference, however, is that instead of a service provider subsidizing one side of the platform, neither side needs subsidies. Such an approach is the current primary revenue business model of traditional (human-driven) P2P ride-hailing companies such as Uber, Lyft, Sidecar, Didi Chuxing, Go-Jek, Grab Taxi, Haxi, and so on.

This business model falls within the traditional definition of multi-sided business platforms [8], [19], [20], in which the platform operator matches individuals with vehicles and extra time to drive them, with people who need rides, taking a commission on each ride [45]. However, differently from scenario A, the company does not need to own the fleet, it simply connects supply with demand and creates value in the process.

According to the Delphi Automotive CEO, Kevin Clark: "while current estimates for AVs embedded technology range from $\$ 70,000$ to $\$ 150,000$, the cost of such autonomous driving stack by 2025 will come down to about $\$ 5,000$ because of technology developments and higher volume" [37]. Additionally, shared AVs are predicted to cost less than human-driven taxis and ride-hailing services, but more than human-driven personal vehicles [7].

A couple of propositions can be drawn up for this scenario, the first two based on ordinary people owning AVs (P1 and P2), while the last two are based on car ownership being in the hands of car-rental companies (P3 and P4):

- P1: AVs owners (ordinary peers) making their AVs available to P2P ride-hailing companies; and

- P2: P2P car-rental companies making their clients' AVs available to P2P ride-hailing companies.

Whether and when AVs come on stream in volume, more and more ordinary consumers would be able to afford one. Thus, for those who are interested, a new income opportunity may arise, given that a car remains on the average, $95 \%$ idle: either parked at home, work or elsewhere [38]; hence, an AVs owners could make their cars available for third-party usage, by directly renting their car to a P2P ride-hailing company, such as Uber and Lyft (P1); or by making it available on a P2P car-rental platform such as: Getaround, Turo, Drivy, Ouigo, Parpe, etc., which, in turn, via partnerships, would provide the vehicle to P2P ride-hailing companies (P2).

From the perspective of ordinary AVs' owners, there are no clearly significant differences in the advantages offered by $\mathbf{P 1}$ or P2 (for now); however, from the P2P carsharing companies' standpoint, hiring someone else's car from a P2P car-rental company might bring advantages, regarding strategic agreements on data exchange.

Notwithstanding, these two hypotheses may prove unfeasible due to the relationship that humans have with their cars. According to Belk [39], some possessions (like cars) become an extension of self; which makes it difficult for people to lend or even dispose of such goods. Furthermore, Steg [40] enumerates the three main motives for car usage as being instrumental, affective and symbolic; therefore, depending on how high the last two are for certain individuals, the possibility of this type of business might be hindered.

- P3: traditional car rental companies make their AVs available to P2P ride-hailing companies.

- P4: traditional car-rental companies become P2P ride-hailing companies. 
Today, in the context of $\mathrm{P} 2 \mathrm{P}$ ride-hailing, there is an idle contingent of drivers who are willing to provide services, but who unfortunately do not own a car. Aiming at tapping this unexplored market, traditional car-rental companies such as Unidas and Localiza Hertz, are forming partnerships with $\mathrm{P} 2 \mathrm{P}$ ride-hailing companies, so that these drivers can rent cars and start generating revenue. Considering a future context in which AVs might also be available for rental by these traditional car-rental companies (P3), it is plausible to imagine that such a kind of partnership will prevail. The difference would be in the absence of the driver, but it would still be a win-win situation for both car rental and P2P companies.

Lastly, one can also foresee car-rental companies seizing the opportunity to become P2P ride-hailing companies themselves (P4), since they would already own the AV fleet. In such a case, these companies would become "one-way multi-sided platforms"; which places them within scenario A.

\subsection{Scenario C: B2C multimodal mobility}

Moving the analysis to the upper quadrants of Fig. 1, we are now considering getting from point A to B by using a bundle of transport modes; therefore, within this context, AVs would be seen as only one among many transport options within urban centers. For this kind of scenario $(\mathrm{C}$ and $\mathrm{D})$, an interesting premise posed by many scholars is that AVs could be very useful in helping to solve the first- and last-mile issues [41], which according to the authors are the most constraining parts of an urban commute, as the conventional transport modes for these stages of the trip can (in many cases) be rather slow, inflexible and not provide a seamless experience to passengers.

Scenario C entails one-way multi-sided platforms offering bundled transport solutions. That is, that a single firm, by subsidizing the consumer segment, will offer complete journeys from point $\mathrm{A}$ to $\mathrm{B}$ via a combination of transport modes. An attempt towards this type of business model was the one planned for Las Vegas during the years of 2013 to 2015: "SHIFT - Project 100". According to Kamargianni et al. [6], this approach, in which multiple modes are owned and operated by one company, is very unique.

By owning all the vehicles in its fleet, SHIFT - Project 100 aimed at offering bundled mobility services, including $100+$ on-demand drivers, $100+$ shared cars, $100+$ shared bikes, and $100+$ shared shuttle bus stops, as well as a valet service [6], [42]. The project was ICT integrated; therefore, users could choose the destination in the app planning tool and a choice of transport modes would automatically be made for these users [5], [6]. Furthermore, the project also provided a variety of membership levels (each with a designated amount of trip time each month), where these pre-paid monthly packages allow customers to pay for all their usage beforehand and at once [6].

This project, however, was canceled before its operation even began. The major claim for the premature shutdown, according to the company's CEO Zach Ware, was that from the original 100 Model S that they had ordered from Tesla Motors, they only received 10 to 20 in June of 2014, and never did take delivery of the full 100 cars [42]. To date, no other real-life examples for scenario $\mathrm{C}$ were found, neither in academic nor grey literature. In such a scenario, by owning and managing all the multimodal fleet, the service provider would have control of all user data, as well as bargaining power with other public and private stakeholders in its ecosystem. 


\subsection{Scenario D: B2C + P2P multimodal MaaS}

By offering multimodal mobility via two-way multi-sided platforms, scenario D is likely to be the most complete, but also the most complex, of all four. The claim is that the service operator or the platform firm (third party; public transport provider or public entity) would match producers (public and private suppliers of multimodal transport services) with consumers (commuters). The complexity lies in the bundled offering of private and public transportation modes by multiple companies (both $\mathrm{B} 2 \mathrm{C}$ and $\mathrm{P} 2 \mathrm{P}$ ), via a single user interface.

The premise falls within the definition of MaaS [10], [11], [12], in which tailor-made mobility packages are created to fit individual traveler's needs and requirements, delivering multimodal transport solutions via a single interface of a service provider. Thus, unlike scenario $\mathrm{C}$, the platform firm does not need to own the multimodal fleet (even though scenario $\mathrm{C}$ also fits within MaaS broad definitions).

As listed by other studies [5], [6] in their critical literature reviews, several examples of MaaS schemes can be found worldwide. The first authors listed 12 and the next, 15, all held in developed countries. The most integrated MaaS model listed by both groups of authors was the Swedish project UbiGo, which consisted of a pilot tested in the city of Gothenburg from 2012 to 2014, involving cooperation between a public transport operator (Vasttrafik); car sharing; and car rental, taxi and bike sharing companies (Sunfleet, Hertz, TaxiKurir and JCDecaux, respectively). The ICT, payment and ticket integrated service combined everything into one application (provided by Ericsson AB).

Another interesting example came in 2016 from Helsinki, Finland, in which a group of eight investors led by Transdev, teamed up forming a MaaS operator named Whim [43]. Similar to UbiGo, it offers a subscription of various transport modes (public transportation, car-sharing, taxi and bike-sharing) under one contract. Several other, similar examples are spreading worldwide, to name a few: Moovel in Germany; Smile in Vienna, Austria; My Cicero in Italy; TransitApp in North America, Europe and Australia [5], [6]. Therefore, MaaS is proving to be an interesting alternative for urban mobility issues.

Within MaaS-related literature, AVs are considered as an important future transport mode [3], [5], [10], [14], [29], [43], in the sense that AVs open doors to new mobility business models that are embedded in the smart development of cities [16].

Furthermore, the global MaaS market will exceed $\$ 10$ trillion in gross revenue by the early 2030s, while sales from AVs will total about $\$ 900$ billion at that time, or roughly one-tenth of the services market, which represents more than 30 times the size of the taxi industry today [14]. A benchmark study carried out for BMCP and Mo'Veo [44], stated that just in 2017 alone, there were 64 programs involving experimentations with autonomous and connected vehicles running worldwide, of which more than 50\% were in Europe.

Lastly, investors may be undervaluing MaaS severely today, and in 5 years' time, autonomous taxi networks could command a market capitalization of over $\$ 5$ trillion [14]; however, it is worth noting that governance is likely to be the most challenging aspect about scenario D, as implementation of MaaS could have a significant impact on the existing business model of public transportation, especially at the level of integration with private actors [5]; therefore, deciding who will be the platform provider and how value is likely to be created and distributed will become some of the major challenges, as MaaS, in theory, is much simpler than in practice. 


\subsection{Scenarios' synthesis}

After thoroughly analyzing each scenario, it is possible to state that scenarios A and B will not be configured as MaaS schemes; given that an important premise within MaaS literature is the integration of multiple transport modes to deliver tailor-made mobility solutions to users. Thus, considering that such scenarios aim to deliver single transport mode solutions, the best business model to be applied soon is P2P ride-hailing, alongside the theory of business platforms.

On the other hand, scenarios C and D both do fall within the MaaS definition, which entails a complex network of stakeholders (with both private and public actors delivering bundled tailor-made multimodal mobility for users). The theory on business platforms is useful to some extent: understanding the underlying logic of the core interactions to be carried out by the service provider, while connecting producers (transport providers) to consumers (demanders of mobility); however, such a theory is limited to explaining the complexity of all stakeholders involved in MaaS schemes. In this sense, the theory on business ecosystems [21] might prove useful for these scenarios [29].

\section{CONCLUSION}

With the aim of creating business platform scenarios for AVs within urban mobility contexts, the present study sought to design and exemplify four distinct scenarios for future mobility business solutions.

Scenario A encompasses unimodal mobility delivered by a single firm subsidizing the consumer segment. Companies like Uber, Lift and Waymo are already testing their AVs B2B ride-hailing services in several American cities. Meanwhile, scenario B also delivers unimodal mobility, but no side of the platform is subsidized: this is the current business model of P2P ride-hailing companies, by hiring freelance drivers. When AVs come onstream in volume, such a scenario might prevail in generating revenue for Avs' owners. Traditional car rental companies, with their autonomous fleets, could also benefit from scenario B, by renting their AVs directly to P2P ride-hailing companies or by becoming a P2P ride-hailing company themselves.

Scenario C is the most unlikely to be consolidated, as can be corroborated by SHIFT's Project100 in Las Vegas, which was discontinued before it even started. Lastly, scenario D proves to be the most complete, but also the most complex in execution among them all. By delivering multimodal solutions via two-way multi-sided platforms, governance of this ecosystem might be its most constraining aspect, as orchestrating public and private transportation offerings via a single platform service can be quite challenging.

Besides the unlikelihood of scenario $\mathrm{C}$, we believe that any of the other scenarios have the potential to become a reality. We also believe in the evolving aspect of urban mobility, in that scenario A is already being tested at a small scale, and it could grow and evolve towards scenario B predominance (with the service provider suspending subsidies), or even scenario D, with $\mathrm{B} 2 \mathrm{C}$ and/or P2P AV companies becoming one among the many modals within the MaaS schemes (the same goes for scenario B, which could also grow and evolve towards D).

For scenarios $\mathrm{A}$ and $\mathrm{B}$, the prevailing business model is likely to remain as $\mathrm{P} 2 \mathrm{P}$ ride-hailing, supported by the theory of business platforms. While for the upper quadrants' scenarios, MaaS seems to be the most coherent business strategy, having both business platform and ecosystem theories as guidelines. In this sense, we infer that AVs may act as catalysts in accelerating the transition towards mobility "servitization", especially in 
scenarios $\mathrm{C}$ and $\mathrm{D}$, where AVs might be well fitting as a transport mode for first- and last-mile issues, as well as for any microtransit typologies.

Lastly, by being a prospective study based on secondary data, the present research lacks empirical evidence to test the scenarios. Further studies are needed to test such scenarios' feasibility, as well as to corroborate or refute our inferences. We also suggest deeper studies on whether one-way or two-way platforms are the best solutions for inserting AVs into urban mobility contexts, as well as to corroborate the evolutive aspects of the scenarios, identifying the main involved stakeholders and how value will be generated and distributed among the ecosystems. Further studies are needed on MaaS, first to understand whether this new concept could be described as a business model, and second, to test the feasibility of MaaS schemes within developing countries, as well as the viability of inserting AVs in such contexts.

\section{ACKNOWLEDGEMENTS}

This paper would not have been possible without the support and funding of the Laboratoire Génie Industriel in CentraleSupélec, France; the support of the Post-Graduate Program in Administration of Universidade Federal de Lavras (PPGA/UFLA) in Brazil; and the Terrestrial Mobility Laboratory of Universidade Federal de Lavras (LMT/UFLA) in Brazil. We also would like to thank the following Brazilian founding agencies: Coordenação de Aperfeiçoamento de Pessoal de Nível Superior (CAPES) and Conselho Nacional de Desenvolvimento Científico e Tecnológico (CNPq).

\section{REFERENCES}

[1] Fournier, G., The new mobility paradigm: Transformation of value chain and value proposition through innovations. The Automobile Revolution: Towards a New Electro-Mobility Paradigm, ed. D. Attias, Gewerbestrasse, p. 148, 2017.

[2] Attias, D., The automobile world in a state of change: From the automobile to the concept of auto-mobility. The Automobile Revolution: Towards a New Electro-Mobility Paradigm, ed. D. Attias, 1st ed. Gewerbestrasse, p. 148, 2017.

[3] Johnson, M. \& Mena, C., Supply chain management for servitized products: A multi-industry case study. International Journal of Production Economics, 114(1), pp. 27-39, 2008.

[4] Amirkiaee, S.Y. \& Evangelopoulos, N., Why do people rideshare? An experimental study. Transportation Research Part F, 55, pp. 9-24, 2018.

[5] Jittrapirom, P. et al., Mobility as a Service: A critical review of definitions, assessments of schemes, and key challenges. Urban Planning, 2(2), pp. 13-25, 2016.

[6] Kamargianni, M. et al., A critical review of new mobility services for urban transport. Transportation Research Procedia, 14, pp. 3294-3303, 2016.

[7] Litman, T., Autonomous vehicle implementation predictions: Implications for transport planning. Report for Victoria Transport Policy Institute, 2018.

[8] Parker, G.G., Van Alstyne, M.W. \& Choudary, S.P., Platform Revolution: How Networked Markets are Transforming the Economy and How to Make Them Work for You, W.W. Norton \& Company: New York, p. 352, 2016.

[9] Melis, A. et al., CrowdSensing for smart mobility through a service-oriented architecture. Proceedings of the Smart Cities Conference (ISC2), 2016 IEEE International, p. 2, 2016.

[10] Mulley, C., Mobility as a Services (MaaS) - Does it have critical mass? Transport Reviews, 37(3), pp. 247-251, 2017.

[11] Hietanen, S., "Mobility as a Service" - The new transport model? Eurotransport, 12(2), pp. 2-4, 2014. 
[12] Karlsson, I.C.M., Sochor, J. \& Strömberg, H., Developing the "Service" in Mobility as a Service: Experiences from a field trial of an innovative travel brokerage. Transportation Research Procedia, 14, pp. 3265-3273, 2016.

[13] Zhang, J. et al., Data-driven intelligent transportation systems: A survey. IEEE Transactions on Intelligent Transportation Systems, 12(4), pp. 1624-1639, 2011.

[14] Keeney, T., Mobility-as-a-Service: Why self-driving cars could change everything. Report by ARK Invest, 2017.

[15] Lang, N. et al., Self-driving vehicles, robo-taxis, and the urban mobility revolution. Report by Boston Consulting Group and World Economic Forum, 2016.

[16] Attias, D. \& Mira-Bonnardel, S., How public policies can pave the way for a new sustainable urban mobility? The Automobile Revolution: Towards a New Electro-Mobility Paradigm, ed. D. Attias, Gewerbestrasse, p. 148, 2017.

[17] Tukker, A., Eight types of product-service system: Eight ways to sustainability? Experiences from suspronet. Business Strategy and the Environment, 13, pp. 246-260, 2004.

[18] Osterwalder, A. \& Pigneur, Y., Business Model Generation: A Handbook for Visionaries, Game Changers, and Challengers, John Wiley \& Sons: New Jersey, p. 278, 2010.

[19] Evans, P.C. \& Gawer, A., The rise of the platform enterprise a global survey. Report by the Center for Global Enterprise, 2016.

[20] Casey, T.R. \& Valovirta, V., Towards an open ecosystem model for smart mobility services: the case of Finland. Report by VTT Technology, 2016.

[21] Moore, J.F., Predators and prey: A new ecology of competition. Harvard Business Review, 71(3), pp. 75-86, 1993.

[22] Muegge, S., Platforms, communities and business ecosystems: Lessons learned about technology entrepreneurship in an interconnected world. Technology Innovation Management Review, 3(2), pp. 5-15, 2013.

[23] Malhotra, N., Pesquisa de Marketing: Uma Orientação Aplicada, 3rd ed., Bookman: Porto Alegre, 2001.

[24] Gil, A.C., Como Elaborar Projetos de Pesquisa, 4th ed., Atlas: São Paulo, 2008.

[25] Fontanella, B.J.B., Ricas, J. \& Turato, E.R., Amostragem por saturação em pesquisas qualitativas em saúde: Contribuições teóricas. Cadernos Saúde Pública, 24(1), pp. 17-27, 2008.

[26] Bardin, L., Análise de Conteúdo, Editora 70: Lisbon, 2010.

[27] Helbig, N. et al., The future of the automotive value chain: 2025 and beyond. Report for Deloitte Consulting, 2017.

[28] Beiker, S., Deployment scenarios for vehicles with higher-order automation. Autonomous Driving: Technical, Legal and Social Aspects, eds Mauer, M. et al. Springer Open: Berlin, 2016.

[29] Corwin, S., Jameson, N., Pankratz, D.M. \& Willigmann, P., The future of mobility: What's next? Report by Deloitte University Press, 2016.

[30] Ambrosino, G. et al., Enabling intermodal urban transport through complementary services: From flexible mobility services to the shared use mobility agency. Research in Transportation Economics, 59, pp. 179-184, 2016.

[31] Silver, D., Self-driving cars: Miles driven, Medium, https://medium.com/self-drivingcars/miles-driven-677bda21b0f7, 2018.

[32] Tascarella, P., Uber debuts self-driving cars for Pittsburgh customers. Pittsburgh Business Times, 14 September, 2018. 
[33] Gibbs, S., Uber plans to buy 24,000 autonomous Volvo SUVs in race for driverless future. Guardian, 20 November, 2017.

[34] Kokalitcheva, K., GM and Lyft Will test self-driving taxis within the next year. Fortune, 5 May, 2016.

[35] Isaac, M., Lyft adds Ford to its list of self-driving car partners. New York Times, 27 September, 2017.

[36] Crum, R., Lyft's self-driving technology finds momentum in Concord. The Mercury News, 8 March, 2018.

[37] Lienert, P., Self-driving costs could drop 90 percent by 2025, Delphi CEO says. Reuters, 4 December, 2017.

[38] Klappenecker, A., Lee, H. \& Welch, J.L., Finding available parking spaces made easy. Ad Hoc Networks, 12, pp. 243-249, 2014.

[39] Belk, R.W., Possessions and the extended self. Journal of Consumer Research, 15(2), pp. 139-168, 1988.

[40] Steg, L., Car use: Lust and must. Instrumental, symbolic and affective motives for car use. Transportation Research Part A: Policy and Practice, 39(2-3), pp. 147-162, 2005.

[41] Scheltes, A. \& Correia, G.H.A., Exploring the use of automated vehicles as last mile connection of train trips through an agent-based simulation model: An application to Delft, Netherlands. International Journal of Transportation Science and Technology, 6(1), pp. 28-41, 2017.

[42] Loveday, E., Las Vegas' Project 100 goes bust - Project's Tesla Model S EVs sold off. Insideeds, 13 August, 2015.

[43] Goodall, W. et al., The rise of mobility as a service: Reshaping how urbanites get around. Deloitte Review, 70, pp. 111-129, 2017.

[44] Charlet, M. \& Chaufrein, M., Benchmark de experimentations vehicules autonomes et connectes. Report, 2017. (In French.)

[45] Macmurdo, M., Hold the phone! "Peer-to-peer" ridesharing services, regulation, and liability. Louisiana Law Review, 76(1), pp. 308-353, 2015. 